\title{
Descending Necrotizing Cervicomediastinitis Secondary to Esophageal Perforation: Management in a Hospital with Limited Resources
}

\author{
${ }^{1}$ Sofia Arízaga, ${ }^{2}$ Edgar Bruck Rodas, ${ }^{3}$ Raul Pino, ${ }^{4}$ Jeovanni Reinoso, ${ }^{5}$ Juan Carlos Salamea
}

\begin{abstract}
The esophageal perforation is the result of an iatrogenic cause, spontaneous cause or external trauma. The injury belonging to trauma can have different etiologies, such as the ones that are caused because of strange bodies or caustic substances. Within complications that can appear in esophageal perforation, we have the descending necrotizing mediastinitis, which is a mediastinal infection that starts in the oropharyngeal area. The spread of the infection through the anatomical spaces to the mediastinum can produce a mortality of $67 \%$.
\end{abstract}

Keywords: Esophageal perforation, Trauma, Mediastinitis, Infection.

How to cite this article: Arízaga S, Rodas EB, Pino R, Reinoso J, Salamea JC. Descending Necrotizing Cervicomediastinitis Secondary to Esophageal Perforation: Management in a Hospital with Limited Resources. Panam J Trauma Crit Care Emerg Surg 2015;4(1):23-29.

Source of support: Nil

Conflict of interest: None

\section{RESUMEN}

La perforación de esófago puede ser el resultado de causa iatrogénica, trauma externo o de forma espontánea. En las lesiones que pertenecen a trauma se encuentra los causantes por cuerpos extraños y cáusticos. Dentro de las complicaciones que se presentan por trauma de esófago se encuentra la mediastinitis necrotizante descendente, que es una infección mediastínica que inicia a nivel de la región orofaríngea y se caracteriza por su diseminación a través de los espacios faciales directamente hacia el mediastino con una mortalidad del $67 \%$.

Palabras claves: Perforación esofágica, Trauma, Mediastinitis, Infección.

\footnotetext{
${ }^{1}$ Medical Student, ${ }^{2-5}$ Professor

${ }^{1}$ Medical School, University of Azuay, Ecuador

${ }^{2,5}$ Department of Trauma and Acute Care Surgery, Vicente Corral Moscoso Hospital, University of Azuay, Ecuador

${ }^{3,4}$ Department of Trauma and Acute Care Surgery, Vicente Corral Moscoso Hospital, Cuenca University, Ecuador

Corresponding Author: Juan Carlos Salamea, Professor Department of Trauma and Acute Care Surgery, Vicente Corral Moscoso Hospital, University of Azuay, Ecuador, Phone: 59374096597, e-mail: jsalamea@gmail.com
}

\section{INTRODUCTION}

Esophageal perforation is an infrequent entity, potentially lethal and with a variable clinical presentation as well as a different of treatment possibilities. Prognosis is greatly dependent on early recognition, prompt therapeutic intervention and the presence of associated complications, such as necrotizing mediastinitis at the time of presentation. ${ }^{1}$

Descending necrotizings mediastinitis secondary to esophageal perforation is an infrequent injury encountered in the emergency room, its diagnosis and treatment require a high index of suspicion and judicious analysis of clinical data. Delay or inadequate treatment has a negative impact on morbidity ${ }^{2}$ and mortality can range between 64 and $90 \%$ when treatment is begun after 24 hours. ${ }^{3}$

Ingestion of foreign bodies is a common cause in children, elderly and patients with mental problems. Eighty to ninety percent of the time, these foreign bodies traverse the esophagus uneventfully; however, occasionally they can become stuck in the anatomical narrowings of the esophagus increasing the risk of perforation and infection. ${ }^{4}$ Surgical intervention is indicated when perforation, fistula or inability to remove the foreign body endoscopically. When esophageal perforation has occurred, the patients condition can deteriorate rapidly with a high morbidity and mortality. ${ }^{5}$

The most common complication of esophageal perforation is septic mediastinitis, with 16 to $46 \%$ of patients succumbing to septic shock and multisystem organ failure. ${ }^{6}$

The extension of an oropharyngeal infections to the mediastinum, pleural spaces and adjacent thoracic tissues produces descending necrotizings mediastinitis. The most common causes of this disease are infections of the oral cavity, submandibular, retropharyngeal and deep cervical abscesses. ${ }^{7}$ The risk of descending necrotizings mediastinitis increases with comorbidities, such as diabetes mellitus, immunosuppression and drug abuse. ${ }^{8}$

The aim of this study is to show the experience in management of descending necrotizings mediastinitis of a newly created trauma and acute care surgery service in a regional hospital.

Paper presented in research competition in the PTS Congress, Panama, 2014. 


\section{MATERIALS AND METHODS}

Study design: This is longitudinal, descriptive study based on information retrieved from our prospectively collected database of our trauma and acute care surgery service in a regional hospital (Vicente Corral Moscoso), Cuenca, Ecuador.

Patients and methods: We included all patients whom where diagnosed in our emergency department with descending necrotizings cervicomediastinitis secondary to esophageal perforation between October 2012 and May 2014.

\section{RESULTS}

In a 20 months period, we had eight cases (Table 1), mean age was 40 years, $5(62.5 \%)$ males and $3(37.5 \%)$ females. All patients were admitted through the emergency department due to esophageal trauma complicated with descending necrotizings cervicomediastinitis. The mechanism of esophageal injury was by foreign bodies in six patients $(75 \%)$ and corrosive substances in two patients (25\%); foreign bodies included three dental prosthesis $(37.5 \%), 1$ glass fragments $(12.5 \%), 1$ chicken bone (12.5\%), 1 fish bone (12.5\%) (Table 2).

The mean time from injury to arrival in the emergency department was 5 days, while the mean time to surgical intervention once the patients arrived was 1.3 hours. Mean hospital length of stay (HLOS) was 20 days and mean ICU length of stay (ICULOS) was 7 days. Of the eight patients, two (25\%) succumbed to due to sepsis and multisystem organ failure. All patients had the following symptoms: odinodysphagia, fever, tachypnea and subcutaneous cervical crepitation.

The most common procedures performed werecervicotomy with drainage of the deep cervical fascia and esophagostomy in $100 \%$ of the patients. A feeding jejunostomy was performed in $75 \%$ of the patients, followed by a thoracotomy with drainage of the mediastinum in 50\% of the patients. A total gastrectomy and thoracostomy in $25 \%$ of the patients. Mean acute physiology and chronic health II (APACHE II) score was 13.1 (7-18). The mean risk of death was $17.7 \%$ (7.6-29.1\%).

\section{DISCUSSION}

Esophageal perforation is a rare and potentially lethal injury, with various treatment options depending on the clinical presentation. Its prognosis greatly depends on early recognition and opportune treatment as well as the presence of associated complications, such as descending necrotizings cervico-mediastinitis. ${ }^{9}$

More than half of the esophageal perforations are iatrogenic in nature (dilatation and endoscopy), those related to trauma account for roughly $30 \%$, and spontaneous perforations are less than $10 \%$. Injuries caused by foreign bodies and caustic ingestion usually occur at the point of anatomical narrowing. ${ }^{10}$ As depicted in Table 2, 75\% of our cases were due to foreign bodies, the majority of which were dental prosthesis. Caustic substances (caustic soda and nitric acid) were responsible for 25\% of the injuries with the ensuing descending necrotizings cervicomediastinitis.

Esophageal injuries due to foreign bodies occur more often in the elderly, children, psychiatric patients and those with dental prosthesis. The majority of these objects become lodged in the cervical esophagus, and the literature sustains that only $14 \%$ are due to dental prosthesis, and $32 \%$ due to bones in food (especially fish bone) and other food particles $26 \% .^{11}$ Our case series has similar findings regarding these ethiologic factors.

Esophageal perforations are rare, with 0.5 to 5 cases/ year; however, they are considered the most serious of the digestive tract as approximately $20 \%$ will develop a complication: abscesses, fistulas, and sometimes mediastinitis which is associated with an elevated mortality. ${ }^{12}$

The main complications with a foreign body include mucosal erosions, abrasions and perforations with the progression of peritonitis, mediastinitis, pneumothorax, pleural effusions, empyemas and chemical pneumonitis., ${ }^{9}$

The esophagus is a hollow organ of the digestive tract in close relation with cervical, mediastinal and abdominal structures during its course inferring different clinical significance. Lacking of serosa leaves, it susceptible to perforations when the mucosa is injured then exposing its contents into the mediastinum. Therefore, any breach of its integrity will be considered an infectious process. ${ }^{9,11-13}$

The diagnosis of mediastinitis with immediate infectious signs is present in $31 \%$ of the cases; in less than 6 hours infectious signs will be present in $72 \%$ of the cases, between 6 and 24 hours, it increases to $87 \%$ and in 48 hours, it increases to $97 \%$. As the time to diagnosis and intervention increase infectious signs and the patients in our series presented to our facility late (mean time of 5 days), the infectious process was advanced; therefore, our mortality was $25 \%$.

The most common symptom in esophageal perforation is pain $(70 \%)$, the most common sign is subcutaneous emphysema (66\%). Perforation of cervical esophagus is manifested with subcutaneus emphysema, tracheal deviation, hemoptysis and dysphonia; dysphagia and odynophagia may or may not be present. With treatment the clinical picture progresses with fever, tachypnea, tachycardia, erythema, crepitation, drainage through the wound and abscess formation (the first three associated with mediastinitis and sepsis). ${ }^{10,13}$ 


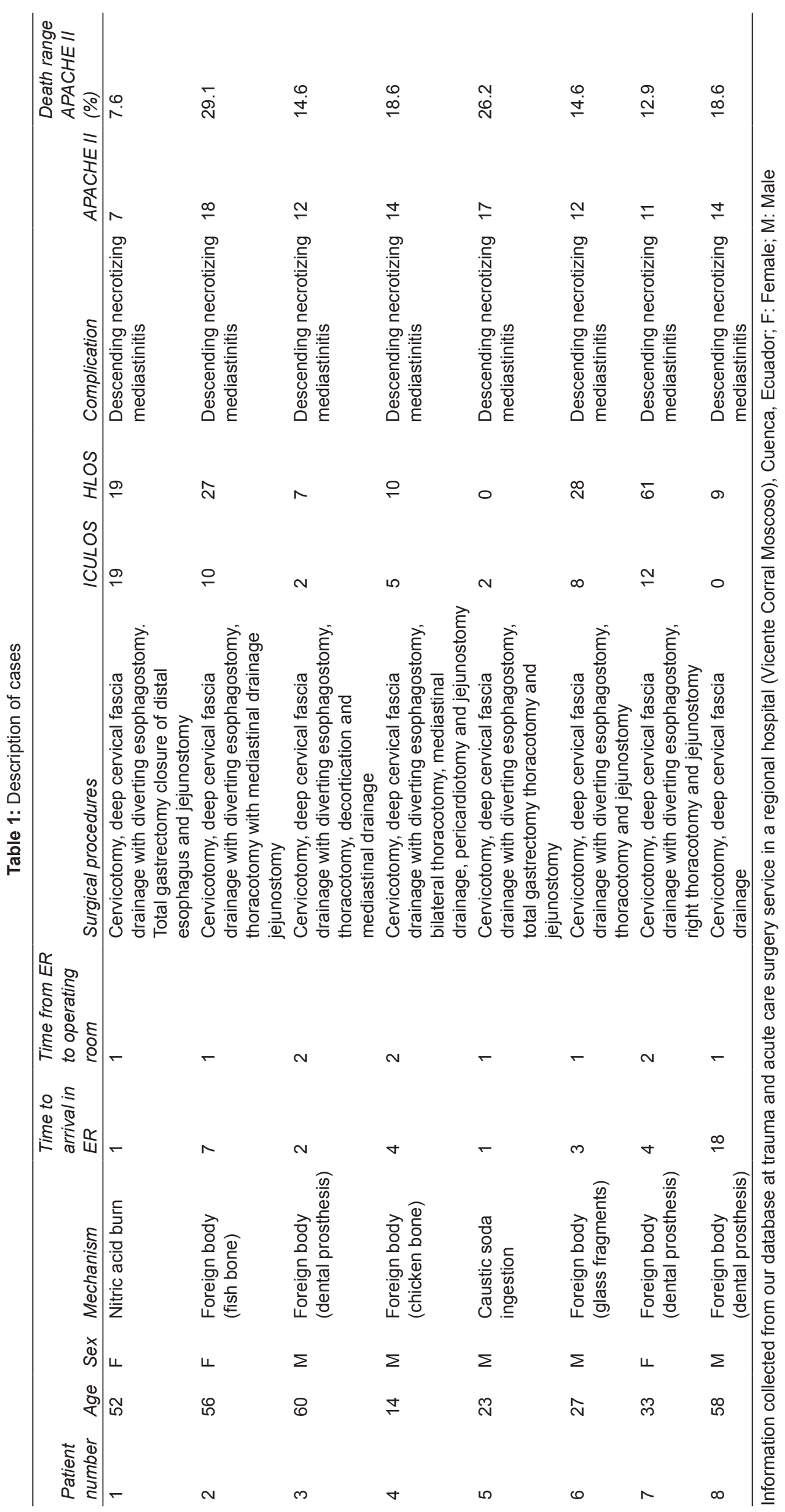


Table 2: Description of cases based on injury mechanism

\begin{tabular}{ll}
\hline Foreign body (dental prosthesis) & $3 / 8(37.5 \%)$ \\
Foreign body (glass fragment) & $1 / 8(12.5 \%)$ \\
Foreign body (fish bone) & $1 / 8(12.5 \%)$ \\
Foreign body (chicken bone) & $1 / 8(12.5 \%)$ \\
Nitric acid burn & $1 / 8(12.5 \%)$ \\
Caustic soda ingestion & $1 / 8(12.5 \%)$ \\
Foreign bodies & $75 \%$ \\
Caustic substances & $25 \%$ \\
\hline
\end{tabular}

Information collected from our database at trauma and acute care surgery service in a regional hospital (Vicente Corral Moscoso), Cuenca, Ecuador

In contrast, the patients in our series presented with odynophagia and dysphagia, fever, tachypnea and crepitation.

Acute mediastinitis is a severe process that occurs as a consequence of esophageal perforation or that ensues as a complication of cardiothoracic trans-sternal procedures, and infrequently can develop after an infectious process of the oropharynx that extends into the cervical region and then into the mediastinum via the fascial panes. ${ }^{14}$

Descending necrotizings cervicomediastinitis can occur after an injury in the oral or pharyngeal regions, producing an infectious process, such as empyema and pericarditis, with a mortality rate that can vary between 14 and $42 \%{ }^{15}$

In some instances, the mediastinitis can be treated by draining the mediastinum transcervically. A thoracotomy should be reserved for cases in which the infection extends beyond the carina. Early diagnosis and opportune surgical intervention are paramount in the treatment of this life threatening infection. ${ }^{16}$ In this small case series, deep cervical fascia drainage via cervicotomy with diverting esophagostomy was performed in 100\% of the cases, followed by feeding jejunostomy $75 \%$ of the times, thoracotomy with drainage of the mediastinum in $50 \%$ of the cases, gastrectomy in $25 \%$ of patients, and thoracostomy in another $25 \%$. In each of our cases, early surgical intervention was performed with mean of 1.3 hours since admission to out institution; although the mean time from injury was 5 days which obviously complicated the clinical course, estimated morbidity and mortality of these patients.

Once mediastinitis ensues, and if not treated promptly it can progress to sepsis which can be fatal. ${ }^{17,18}$ Sepsis is the main cause of prolonged ICULOS and HLOS, as evidenced in our series (ICULOS 7.2 days and HLOS 19.7 days).

The most frequent cause of mediastinitis is disruption of the esophageal wall, followed by infections that tract down from the oral cavity pharynx and neck, and secondary to median sternotomy from cardiac surgery. ${ }^{17}$
As previously mentioned, the esophagus lacks of serosa, this along with the negative intra-thoracic pressure facilitate the rapid dissemination of infections into the mediastinum and the pleural cavity. However, perforations of the cervical esophagus, either by instrumentation or foreign bodies tend to evolve favorably with early medical therapy and require surgical treatment only if there are signs of mediastinal or cervical infection, as is the case in this series of patients. ${ }^{17,18}$

The clinical spectrum of mediastinitis is variable; it can be very aggressive reaching sepsis, shock and multi system failure in a few hours, most likely being fatal, or in other instances with a slower course taking a few days to manifest clinically. ${ }^{19}$ In most of our cases, mediastinitis was manifested on admission, with sepsis, shock and multiorgan failure producing the death of two patients.

One should inquire about a history of cervical infections, cervical or thoracic pain (generally, retrosternal), fever, tachycardia, hypotension, malaise and progressive deterioration of the general state of health. During physical examination, it is possible to find cervicothoracic subcutaneous emphysema with tenderness to palpation of the involved area, and signs of pleural occupation in more advanced stages. However, these signs are neither constant nor pathognomonic and the patient can be asymptomatic. ${ }^{20}$

The diagnosis for descending necrotizings cervicomediastinitis was based on the criteria presented by Esterna et al as follows:

- Clinical manifestation of an infection in the oropharyngeal region.

- Radiologic findings consistent with cervicomediastinal injury.

- Demonstration of evident mediastinal infection during surgery, post mortem or both.

- Clear evidence of relationship between the oropharyngeal or cervical infection with descending necrotizings cervicomediastinitis.

It is also important to investigate a possible background of a head and neck infection with a complication of a retropharyngeal of peritonsillar abscess from a dental or oropharyngeal process. ${ }^{21}$

Among Other Useful Tests, We have the following:

- Laboratory: Leukocytosis with a left shift, and elevated C-reactive protein.

- Imaging: Abnormal in 75 to $90 \%$ of patients.

- NeckX-ray; a foreign body, subcutaneous emphysema or retroesophageal air can be seen.

- AP and lateral chest X-ray; pneumomediastinum, pneumothorax, pleural effusion $(80 \%$ on the left side) or subcutaneous emphysema. ${ }^{19,22}$ 
- Esophagogram with hydrosoluble contrast; for the majority of authors, it is mandatory as it confirms the diagnosis and pinpoints the location and magnitude of the injury; however, as in our series, when the clinical setting does not allow for such a test, a CT scan is indicated.

- Neck and chest CT scan with contrast can visualize the level of perforation, identify air and fluid collections in the mediastinum as well as pleural involvement. It is the study of choice to diagnose esophageal hematomas and as a follow-up study. ${ }^{11,12}$

- Rigid esophagoscopy; for some authors mandatory, for others in conjunction with imaging studies as the sensibility for diagnosis increases to close to $100 \%$.

- Secretion cultures; identifies the organism and helps to guide antibiotic therapy. ${ }^{22}$

In this case series, CT scan was utilized as first line diagnostic study along with complete blood count, as well the main studies for follow-up of the in-hospital progression of patients. Esophagograms were used to delineate the anatomy of the esophagus prior to reconstruction.

Treatment: Estera et al recommended trans-thoracic drainage of the mediastinum below the tracheal bifurcation anteriorly, and at the level of the forth thoracic vertebral body posteriorly. Tracheostomy is essential due to the severe respiratory compromise from edema and inflammation. ${ }^{23}$

Treatment objectives: Stabilize the patient, drain collections, control infection and re-establish digestive transit. It could be considered clinical and surgical as follows:

- Clinical: Generally associated to surgical therapy.

- Mediastinitis: Adequate hydration and nutrition (preferably enteral) as these patients are hypercatabolic. Plus antibiotic therapy targeting the isolated microbes cultured from the drained collections (keeping in mind the possible presence of beta-hemolytic Staphylococcus and anaerobes). ${ }^{19}$

- Esophageal perforation: Same indications as in mediastinitis; expectant conduct only in those patients where a total perforation is not evident and there are no signs and symptoms of sepsis. In pediatric patients, it is still controversial. ${ }^{10,12}$

- Surgical:

- Mediastinitis: Aggressive surgical drainage through cervicotomy and/or posterolateral thoracotomy. ${ }^{20,21}$

Lethality of descending necrotizings cervicomediastinitis is high, reaching 29\%; however, aggressive and early surgical therapy in combination with broad spectrum antibiotics are important factors that affect survival in these patients whom have an average HLOS of 41 days. ${ }^{6,723,24,26}$

- Esophageal perforation: Depends on the localization of the perforation, the magnitude of it and the concurrent pathology. In the case of a hypopharyngeal localization, we performed a cervicotomy for drainage, diversion and exclusion; this involves leaving the esophagus in situ and excluding it through a cervical esophagostomy, followed by a feeding jejunostomy. This accomplishes stabilization of the patient (management of sepsis) and proceed with a delayed repair of the esophagus with primary suture (ideal technique). ${ }^{3}$ In our patients, we addressed the problem almost immediately and drastically which improved the clinical condition despite the time elapsed since injury. Reconstruction of the digestive tract can be accomplished in the same setting or delayed (as in our cases) depending on the general state of the patient and the degree of mediastinal contamination. ${ }^{25}$

Prognosis is closely dependent on the cause and localization of the esophageal perforation as well as the treatment given, presence of esophageal disease, associated injuries and nutritional state. ${ }^{5}$ The mean HLOS of patients with penetrating esophageal trauma is 40 days (3-90 days), and the global mortality continues to be high (10-40\%), tending to the high end when resection techniques are involved, and when complications are present (14-67\%), presence of malnutrition (40\%) and delay in treatment $(25-40 \%){ }^{26}$

\section{CONCLUSION}

Esophageal perforation is uncommon but a serious entity. Although diagnosis can be late with associated complications, such as descending necrotizings cervicomediastinitis, it is possible to maintain a lower than the reported mortality rate when the initial treatment is aggressive, such as a cervicotomy with drainage of the deep cervical fascia, esophagostomy, drainage of the mediastinum via thoracotomy, and a feeding yeyunostomy for early enteral nutrition.

\section{REFERENCES}

1. Acín-Gándara D, Limones-Esteban M, Ramos-Lojo B, Delgado-Millán MA, López-Herrero J. Esophageal resection and immediate reconstruction in esophageal perforations. Cir Cir 2010 Nov-Dec;78(6):528-532.

2. Bayarri Lara CI, Sevilla López S, Sánchez-Palencia Ramos A, Alkourdi Martínez A, Hernández Escobar F, Quero Valenzuela F, et al. Surgical management of descending necrotizing mediastinitis. Cirugía Española. Elsevier; 2013 Nov 1;91(9):579-583. Available at: http://www.elsevier.es/en- 
revista-cirugia-espanola-436-articulo-surgical-managementof-descending-necrotizing-90269721.

3. Berreta J, Kociak D, Balducci A, De Feo F, Laplacette MV Bellido F, et al. Peritonitis secundaria generalizada: Predictores de mortalidad y sobrevida, y vinculantes evolutivos de mortalidad. Acta Gastroenterol Latinoam 2010;40(1):105-116.

4. Verdecia Rosés ME, Rodriguez Yero D, Verdecia Rosés Y. Perforación esofágica por cuerpo extraño en una anciana. MEDISAN 2014;18(7):1018-1022. Available at: http://scielo.sld. cu/scielo.php?script=sci_arttext\&pid=S1029-301920140007 00017\&lng=es\&nrm=iso\&tlng=es.

5. Sá MPB de O, Silva DO, Lima EN de S, Lima R de C, Silva FPV, Rueda FG de, et al. Postoperative mediastinitis in cardiovascular surgery postoperation. Analysis of 1038 consecutive surgeries. Rev Bras Cir Cardiovasc 2010;25(1):19-24.

6. Berreta J, Kociak D, Ferro D, Corti R, Balducci A, Marty PF. Mediastinis related to esophagogastric disease and injury. Warning clinical signs and independent predictors of intrahospitalary survival. Acta Gastroenterol Latinoam 2010;40(1):32-39.

7. Deu-Martín M, Saez-Barba M, López Sanz I, Alcaraz Peñarrocha R, Romero Vielva L, Solé Montserrat J. Mortality risk factors in descending necrotizing mediastinitis. Arch Bronconeumol 2010;46(4):182-187.

8. Said S, Cooper CJ, Teleb M, Hernandez GT. Descending Necrotizing Mediastinitis of Odontogenic Origin in a Young Male Patient: Case Report and Discussion. Am J Med Case Reports. Science and Education Publishing; 2014 Jan 23;2(2):44-47. Available at: http://pubs.sciepub.com/ ajmcr/2/2/5/index.html.

9. Vicente V, González M, María D, Palmón T, Hernández FE, Cira IH, et al. Cuerpos extraños esofágicos. Experiencia de treinta y dos años. Esophageal rare bodies. Thirty-two years of experience 1(2):13-23.

10. Nirula R. Esophageal perforation. Surg Clin North Am 2014 Feb;94(1):35-41.

11. García JJC, Peña-Alfaro NSG Ocamp JLC, Merino G. Desgarro esofágico por cuerpo extraño. Acta Médica Grup Ángeles [Internet]. Medigraphic; [cited 2015 May 25];11(2):107-108. 2013;(2):107-108. Available at: http://www.medigraphic.com/ pdfs/actmed/am-2013/am132i.pdf.

12. Kaga $K$, Hida $Y$, Hirano S. Descending necrotizing mediastinitis. Kyobu Geka 2011 Jul 1;64(8):752-757. Available at: http:// europepmc.org/abstract/med/21916190.

13. Bilal MS, Gürer O, Kırbaş A, Yıldız Y, Celebi A. Cardiac reoperation in a patient who previously underwent omentoplasty for postoperative mediastinitis: a case report. J Cardiothorac Surg 2011;6:35.
14. Ridder GJ, Maier W, Kinzer S, Teszler CB, Boedeker CC, Pfeiffer J. Descending necrotizing mediastinitis: contemporary trends in etiology, diagnosis, management and outcome. Ann Surg 2010;251(3):528-534.

15. González Aragoneses F, Moreno Mata N, Orusco Palomino E, Vázquez PelilloJC, Peña González EP, Folque Gómez E. Necrotizing descendent mediastinitis of oropharyngeal origin. Arc Bronconeumol 1996 Oct;32(8):394-396.

16. Honguero Martínez AF, Arnau Obrer A, Fernández Centeno A, Saumench Perramon R, Estors M, Cantó Armengod A. Descending necrotizing mediastinitis: treatment by transcervical thoracic drainage. Arch Bronconeumol 2005;41(5): 293-294.

17. Macrí P, Jiménez MF, Novoa N, Varela G. A descriptive analysis of a series of patients diagnosed with acute mediastinitis. Arch Bronconeumol 2003;39(9):428-430.

18. Diamantis S, Giannakopoulos H, Chou J, Foote J. Descending necrotizing mediastinitis as a complication of odontogenic infection. Int J Surg Case Rep 2011;2(5):65-67.

19. Wong $\mathrm{CH}$, Chang HC, Pasupathy S, Khin LW, Tan JL, Low CO. Necrotizing fasciitis: clinical presentation, microbiology, and determinants of mortality. J Bone Joint Surg Am 2003;85A(8):1454-1460

20. Lancerotto L, Tocco I, Salmaso R, Vindigni V, Bassetto F. Necrotizing fasciitis: classification, diagnosis, and management. J Trauma Acute Care Surg 2012;72(3):560-566.

21. Karkas A, Chahine K, Schmerber S, Brichon PY, Righini CA. Optimal treatment of cervical necrotizing fasciitis associated with descending necrotizing mediastinitis. Br J Surg 2010;97(4):609-615

22. Álvarez-Zepeda C, S PR, S HA S CC, J FG, C RB. Mediastinitis descendente necrotizante. Presentación de tres casos y revisión de la literatura Cir 2002;70(5):350-355.

23. Uwa N, Terada T, Saeki N, Sagawa K, Ogino K, Sakagami M. Clinical features of five patients with descending necrotizing mediastinitis originating from deep neck infection. Auris Nasus Larynx 2010;37(4):530-534.

24. Findikcioglu A, Kilic D, Akin S, Hatipoglu A. Descending necrotizing mediastinitis: treatment of a delayed case. Acta Chir Belg 2007;107(4):462-464.

25. Suga A, Inoue $Y$, Takeichi H, Yamada S, Iwazaki M. A case of an elderly patient treated for descending necrotizing mediastinitis. Gen Thorac Cardiovasc Surg 2011;59(9):623-626.

26. Roccia F, Pecorari GC, Oliaro A, Passet E, Rossi P, Nadalin J, et al. Ten years of descending necrotizing mediastinitis: management of 23 cases. J Oral Maxillofac Surg 2007;65(9): 1716-1724. 


\section{Descending Necrotizing Cervicomediastinitis Secondary to Esophageal Perforation: Management in a Hospital with Limited Resources}

In this award winning manuscript, our colleagues from Cuenca, Ecuador, present a case series of some of the most challenging surgical patients: those with esophageal perforation and descending necrotizing infections in the neck and mediastinum. The manuscripts also offer a good review of how to diagnosis and manage this condition.

While infrequent, necrotizing cervicomediastinitis requires early diagnosis and aggressive management if the patient is to survive, particularly when patients present late to hospital as in this series (average 5 days). Esophageal perforations are a good example of what acute care surgery and trauma have in common. In many hospitals, it is likely that diverse specialists may get involved with these patients (general surgeons, thoracic surgeons, head-andneck ENT surgeons, critical care specialists, etc.) with each one looking into a piece of the patient and resulting in no one 'really' being in charge. In these situations the patients may have a worse outcome than patients with one (but really involved) team of acute care surgeons. In my opinion, these complex patients need a team committed and willing to take the risks and make the decisions. The mortality of $25 \%$ reported reminds us these patients are complicated and many will not survive.

Most perforations are due to iatrogenic 'trauma' (most caused by endoscopy) with the remaining is caused by foreign bodies or caustic ingestion. Once the esophagus is perforated, a rapidly progressing infection may extend into the deep layers of the neck and mediastinum, which if not aggressively managed with prompt surgical interventions, may prove lethal. There is not time to wait. The 'sicker' the patient is (diabetic, immunosuppressed, elderly, etc.), the least their bodies can tolerate untreated septic insults. The less resources the hospital has, the earlier and more aggressive the management has to be. Prompt identification of the level of the perforation followed by immediate repair of the perforation (or esophagectomy), drainage of infected spaces, stomas, drains, antibiotics and life support measures are all essential for the management of these complex patients. There is not a single formula on how to treat patients with esophageal perforation and cervicomediastinitis. As pointed by Sofia Arizaga et al, it is the prompt diagnosis and aggressive surgical management and I add a committed team of competent surgeons, that will offer these patients the best change of surviving this highly lethal condition.

Congratulations for the manuscript winning as the best student paper at the Panamerican Trauma Society Meeting in Panama.

Sandro Rizoli

Professor, Department of Surgery and Critical Care Medicine, University of Toronto Chief of Trauma and Acute Care Service, St Michael's Hospital Endowed Chair in Trauma Care Past President of Trauma Association of Canada, Canada 